\title{
Espacios patrimoniales de intervención múltiple. Conflictos territoriales en torno al Plan de Dinamización Turística de las Médulas
}

\author{
Obdulia Monteserín Abella* \\ Universidad Complutense de Madrid (España)
}

\begin{abstract}
Resumen: Los Planes de Dinamización Turística han constituido un instrumento de planificación turística de base territorial. Requería la cooperación interadministrativa y la coordinación entre firmantes y actores implicados, al diseñar actuaciones articuladas a un proyecto integral. La implementación del Plan en Las Médulas activó conflictos latentes, relacionados con la funcionalidad cultural y turística de la Zona Arqueológica, con desacuerdos entre actores locales y con la gerencia del Plan. La yuxtaposición de figuras de protección sectorial es otro de los factores que suma a la compleja intervención en este territorio, debido a las competencias y actuaciones sectoriales por parte de administraciones, instituciones y empresas. Como espacio de intervención múltiple, es necesario el diseño de una estrategia de valorización y gestión integral. Aunque el proceso de valorización integral y el diseño de instrumentos de ordenación son tardíos, la constitución de un órgano de gestión para Las Médulas puede dar respuesta a la problemática planteada.
\end{abstract}

Palabras Clave: Plan de Dinamización Turística; Planificación turística; Gestión turística; Las Médulas; patrimonio; Paisaje Cultural.

Patrimonial spaces of multiple intervention: territorial disputes around The Médulas tourism dynamization Plan

Abstract: Tourism dinamization plans are considered essential in tourism andf land planning. They demanded inter-administrative cooperation and coordination among signatories plus the active intervention of many people and entities ito work towards integral projects. The implementation of the plan for The Médulas triggered off underlying existing conflicts with respect to how tourism is organised in an archaeological zone, and caused deep rifts between local entities in relation to the management plan in that many protective figures overlap in the area and correspond to a multiplicity of actors, both public and private. The area thus requires a comprehensive management plan with clear definition of responsibilities in an overall enhancement of the resource for the good of the community.

Keywords: Plan of tourist promotion; Tourism planning; Territorial tourism management; Las Médulas; Patrimony; Cultural landscape.

\section{Introducción}

Entender el patrimonio territorial como un activo para el desarrollo y aceptar la función turística y social del patrimonio, exige un esfuerzo de conciliación entre los actores de la planificación territorial y de la gestión cultural y turística de los espacios patrimoniales. Abordar el estudio de Las Médulas como espacio patrimonial responde a dos cuestiones principales. En primer lugar, a la propia configuración histórico-geográfica del elemento y al proceso institucional de patrimonialización, que aun no respondiendo a los valores estéticos y hegemónicos del patrimonio clásico, cuenta con diversas figuras de reconocimiento patrimonial y de protección, entre las cuales se encuentra la del Bien de Interés Cultural [BIC], en la categoría de Zona Arqueológica ${ }^{1}$ desde 1996, y la de Patrimonio de la Humanidad

Doctora en Geografía por la Universidad Complutense de Madrid; E-mail: obduliam@ucm.es 
por la UNESCO en la categoría de Paisaje Cultural, desde $1997^{2}$. En segundo lugar, nuestro interés por Las Médulas, gravita en que constituye un espacio de intervención compuesto, al reconocer en este enclave, múltiples dimensiones territoriales -arqueológicas, ambientales y turísticas-.

Es sobre la condición de espacio de intervención múltiple sobre la que tratará nuestro estudio de caso, centrándonos en la aplicación del primer plan de planificación turística en Las Médulas, el Plan de Dinamización Turística Las Médulas, [PDTM]. El Plan revela el problema existente en un territorio de conflictos por la gestión del espacio y el debate entre la funcionalidad cultural y turística, cuyo reto de conciliación se refleja, años más tarde, en el Plan de Adecuación y Usos del Espacio Cultural [PAU] ${ }^{3}$ Las Médulas (2013-2016). Constituye un instrumento público de intervención para la conservación activa, a partir del cual se convocará a los diferentes agentes del territorio para la gestión de las Médulas, a través de la Junta Rectora y Asesora para Las Médulas.

\section{Metodología}

La metodología utilizada se encuadra en una investigación más amplia que tiene por objeto el estudio de la relación entre turismo y desarrollo territorial, concretamente, el papel de los Planes de Dinamización Turística [PDT] de la política turística del Estado, en la interpretación y la valoración del territorio (Monteserín, 2006), centrándonos en este caso, en la planificación y gestión turística en Las Médulas a raíz de las cuestiones planteadas en el Seminario de Investigación: Ciudades Patrimonio de la Humanidad de España y México: experiencias comparadas de planificación y gestión sostenibles ${ }^{4}$.

La hipótesis general es que el PDT favorece la cooperación interadministrativa (Brunet, Almeida, Coll y Monteserín, 2005), el diseño de estrategias integradas para el desarrollo del entorno rural y la conservación activa del patrimonio cultural y natural, y promueve el desarrollo de fórmulas innovadoras de gestión, acordes con las demandas sociales existentes, mediante la construcción de redes que establecen vínculos de carácter horizontal. Sin embargo, a pesar del diseño y el corpus operativo de este instrumento de planificación turística de base territorial, el estudio de caso pone de manifiesto la importancia de la voluntad de participación y cooperación, necesarias entre las diferentes instituciones y responsables locales para que el ya desaparecido PDTM, al igual que otros instrumentos de planificación turística local, pudiera territorializarse de la forma más operativa posible.

El estudio se abordao con una estrategia multimétodo, combinando diversas fuentes -análisis bibliográfico y documentos técnicos, entrevistas a actores del territorio y trabajo de campo-. El texto se estructura en cuatro apartados. En el primero, El proceso de valoración de Las Médulas: las figuras de protección y los actores del territorio (epígrafe 3 ) se realiza una síntesis de los aspectos clave de la patrimonialización de Las Médulas y la complejidad que, para la gestión integral, tienen las figuras de protección sectorial. En segundo epígrafe, titulado El PDTM: un instrumento de cooperación turística fallido, se exponen los principales aspectos territoriales del Plan y su aplicación en Las Médulas. En el apartado Las claves del conflicto en la gestión territorial, se expone la naturaleza de los principales conflictos territoriales. Finalmente, se realizan las conclusiones en relación con las estrategias de actuación para la resolución de conflictos y la gestión integral del Paisaje.

\section{El proceso de valoración de Las Médulas: las figuras de protección y los actores del territorio}

El espacio geográfico en el que se integran Las Médulas ha asistido al declive rural que ha afectado a los sectores económicos tradicionales desde la década de los años 80. Frente al desempleo, envejecimiento de la población, escaso capital de inversión de las administraciones públicas y la capacidad limitada de planificación y gestión local, se suma la fragilidad ambiental y sociocultural, por ser éste un espacio con un alto valor ambiental y cultural que le confiere su condición rural.

La legitimidad patrimonial del territorio ha posibilitado la inclusión de diversos recursos territoriales como factores favorables al desarrollo. Varios documentos incorporan la pluralidad de recursos territoriales para el desarrollo. Destacamos la política territorial europea, plasmada en la Estrategia Territorial Europea [ETE] de 1999, el documento incluye un desarrollo creativo, innovador e inteligente del patrimonio territorial ${ }^{5}$. Otros de los documentos que sientan los antecedentes del reconocimiento del valor patrimonial y social de recursos, en este caso, el paisaje y su integración en las estrategias de desarrollo, es la Convención Europea de Paisaje de $2000^{6}$, ratificada por el estado español, o los Principios Directores para el Desarrollo Territorial Sostenible del Continente Europeo de la Conferencia Europea 
de Ministros responsables de ordenación del territorio [CEMAT] (2000). En el estudio de caso, este reconocimiento se refleja por primera vez en el primer Plan Estratégico de Turismo de Castilla y León (2009-2012) y en el Plan PAHIS de Patrimonio Histórico de Castilla y León (2004-2012) constituyendo, este último, un reconocimiento del potencial de desarrollo que tiene el patrimonio industrial.

La revalorización productiva y estratégica del territorio plantea nuevos retos de ordenación y gestión territorial (Troitiño, 2003), para que la tarea de planificación integre la dimensión paisajística, el desarrollo socio económico, la protección del patrimonio y el consenso ciudadano. La participación ciudadana puede favorecer la aplicación de los instrumentos de planificación. Esta fase constituye ya un nuevo mecanismo para el consenso, establecida en el marco legislativo de la ordenación del territorio (Bouazza, 2014). El turismo, representado por el PDTM, se enfrentó a un gran reto, el de lograr integrarse en la economía y la sociedad local, para promover nuevos productos turísticos, y favorecer un marco óptimo para nuevas oportunidades de revalorización productiva, así integrarse a las dinámicas globales de desarrollo, en un contexto en el que cada vez más, se reconocía la dimensión patrimonial de la arqueología y el paisaje industrial, por parte de la sociedad, los investigadores y los organismos para la conservación del patrimonio industrial y el paisaje cultural (Comité Internacional para la conservación y defensa del Patrimonio Industrial [TICCIH España], Comité Nacional Español del Consejo Internacional de Monumentos y Sitios Histórico-Artísticos, [ICOMOS España], Alianza de Paisajes Culturales Patrimonio Mundial), (Benito, Calderón y Pascual, 2016; Cañizares, 2011; Capel, 1996; Hortelano, 2011; Ortega, 1998; Valenzuela, 2008).

El Paisaje Cultural Las Médulas se localiza al NE de la provincia de León, en un área periférica de la comarca del Bierzo. Tras la inclusión en la lista de Patrimonio de la UNESCO, la declaración como Espacio Cultural por la Junta de castilla y León en $2010^{7}$, constituye una forma de ratificar y enfatizar la inclusión del conjunto en la lista de Patrimonio de la Humanidad. La figura de Espacio Cultural coincide cartográficamente con la delimitación del BIC Zona Arqueológica Las Medulas [ZAM], comprendiendo una unidad territorial que ha pasado de constituir 2.208,2 ha en 1996, a un total de 3.041,3 ha y $68.283,6 \mathrm{~m}$ de perímetro, tras la ampliación territorial del BIC en $2007^{8}$, incluyendo a los núcleos de Médulas y Orellán. (Figura 1).

Figura 1: Área protegida de Las Médulas.

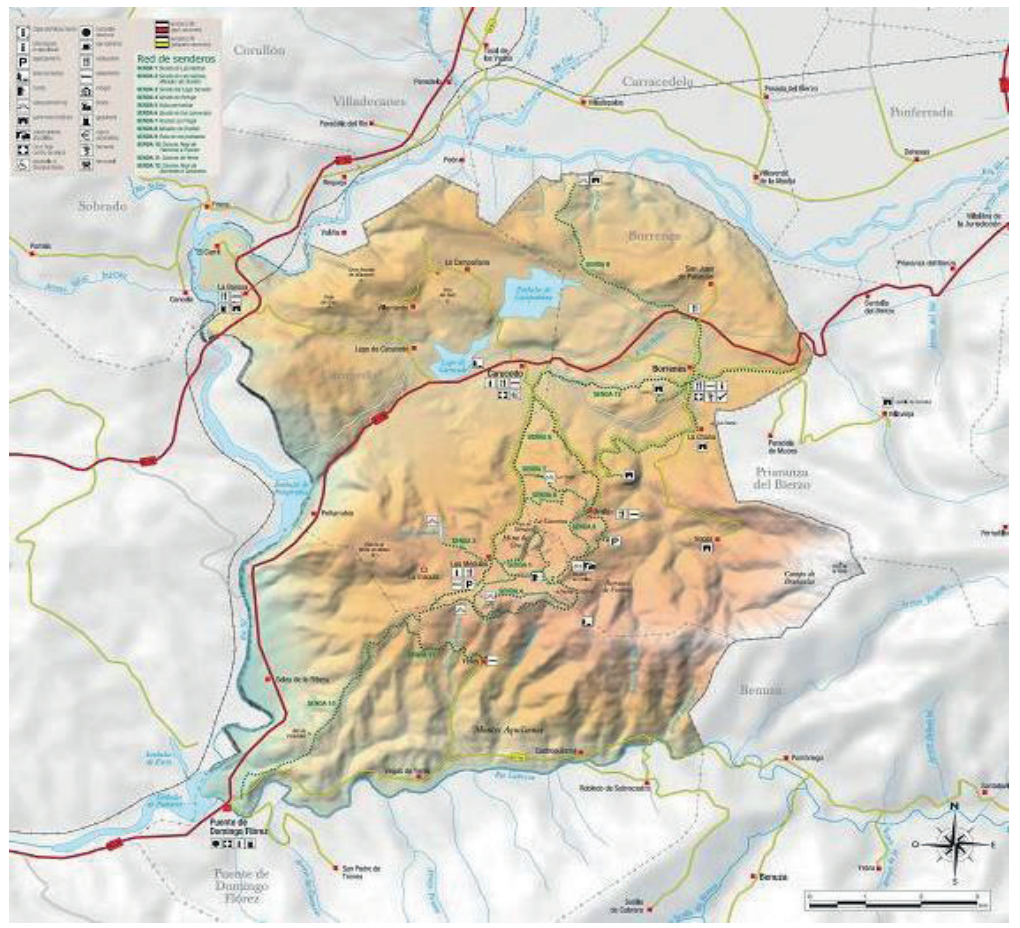

Elaboración propia. 
La configuración de Las Médulas tiene un especial significado debido a las profundas transformaciones culturales, sociales y ambientales que supuso la explotación a cielo abierto en las estructuras existentes (Pérez, Sánchez-Palencia, Fernández, Orejas y Fernández-Posse, 1998). Su origen se encuentra en la llegada de los romanos a la península y, especialmente, al Bierzo, en donde se establece un modelo de explotación que dio lugar al yacimiento aurífero durante el Imperio Romano. El yacimiento fue la mina de oro más importante del Imperio Romano en la península - s. II d.C. -. El Imperio Romano se estable aquí en el año 25 a. C., conformando Gallaecia como parte de la provincia Tarraconense. A partir de entonces, el Bierzo, o Vergel de Flavio, se articuló con Lugo y Astorga a través de una calzada que comunicaba Mérida y Braga (Portugal), con Zaragoza y Tarragona. Además de los cambios en la geopolítica, también dispusieron profundas transformaciones en el modelo de ocupación y en la estructura socio económica preexistente, eminentemente campesina, dejando reconocidos vestigios.

Uno de los vestigios más reconocidos está relacionado con la ingeniería romana, se trata de la técnica ruina montium, que consistía en provocar el derrumbe de montañas por acumulación de agua en la parte alta del yacimiento que, circulando por las galerías construidas, provocaban fuertes riadas de agua. Éstas desembocaban en canales de decantación donde se recogían las pepitas. Esta técnica propició el desarrollo de una importante red hidráulica -con el fin de recoger el agua de lluvia, integrar arroyos, prever deshielos para encauzarlos hacia el yacimiento y la construcción de una presa, correspondiéndose con el lago de Carucedo. Éste se encuentra integrado en la oferta turística de Las Médulas.

La explotación aurífera implicó nada menos que el arrasamiento, durante casi 200 años, de 100 millones de m3 de tierra (Fernández-Posse, Menéndez, y Sánchez-Palencia, 2002). El impacto ambiental en suelo y aguas y el impacto paisajístico de la explotación de oro, no era muy distinto al de las explotaciones mineras de carbón a cielo abierto del Alto Bierzo en época moderna, a excepción del uso de técnicas modernas, que aumentan la toxicidad produciendo los gases y las ondas aéreas de las explosiones. A pesar de la explotación intensiva y devastadora, la imagen que se construyó en torno al yacimiento recabó los aspectos más significantes culturalmente, iniciańdose el proceso de patrimonialización (Díaz, Santana y Rodríguez, 2015, 2013).

La antigua mina romana mide $3 \mathrm{Km}$ de anchura máxima y más de $100 \mathrm{~m}$ de profundidad en el sector más extenso. Las alteraciones en el paisaje se estimaron en 500 ha afectadas, habiendo extraído $950.000 \mathrm{~kg}$ de oro puro (Fernández-Posse et al., 2002); la mayor intervención humana que entonces había sufrido la zona. El yacimiento se había constituido como una fuente de riqueza pero también como un enclave, un nuevo eje de vertebración del espacio. La nueva superficie creada del principal sector minero dio lugar, con posterioridad, a la adecuación del terrazgo para la localidad actual de Médulas.

La configuración histórico-económica de Las Médulas proporciona las claves para entender su valor en la historia de la ocupación del territorio. El proceso de valoración más integrador de que es objeto Las Médulas se encuentra en la declaración de Paisaje Cultural por la UNESCO (1997). Aunque esta declaración se produjo de forma tardía, llegó a superar el reconocimiento sectorial que las figuras de protección anteriores a ésta -BIC, Zona Húmeda Catalogada del Lago de Carucedo (LE- 08) en 1994ํ․ y más antiguamente Monumento Histórico-Artístico- y posteriores declaraciones por la Junta de Castilla y León - Monumento Natural en $2002^{10}$, incluidas parcialmente en la declaración de Zufreiros del Frade, Especímenes Vegetales de Singular Relevancia en 2003, Zona de Especial Protección para las Aves [ZEPA] Montes Aquilanos (ES4130022) en 2000, e incluidas parcialmente en la declaración como (Lugar de Importancia Comunitaria [LIC]) de los Montes Aquilanos y Sierra del Teleno (ES4130117) en 2006, quedando incluido parte del territorio en la red europea de espacios naturales Red Natura $2000^{11}$, además de estar alojado en diversos productos como el Portal Arqueotur-Red de Turismo Arqueológico. A pesar del proceso de patrimonialización y el reconocimiento a través de las declaraciones de su valor, no es hasta la más reciente actualidad cuando se cuestionaría, al fin, la explotación de la cantera de áridos que desde 1986 existe en el Paraje Peña del Rego (Carucedo) en Las Médulas, al ser denegada la explotación en 2015, por la Junta de Castilla y León, a la empresa responsable, alegando razones de incompatibilidad con la valoración de la ZAM y la pertenencia a la Red Natura, poniendo fin a las controversias judiciales-administrativas existentes desde $2011^{12}$.

Paralelamente al proceso de patrimonialización se teje un organigrama complejo de figuras de protección que implican a diversas administraciones y actores (Figura 2). Este hecho demanda la definición de estrategias de planificación e instrumentos de gestión territorial más integrales. Por esta razón, y ante la creciente afluencia de visitantes desde la primera década de 2000 hasta la actualidad, en donde se registran 93.332 visitantes, según las estadísticas del Consejo Comarcal, fue cuando se realizó un estudio de viabilidad y el Anteproyecto de un Parque Arqueológico ${ }^{13}$, dentro del Plan Nacional de Parques de 1993 del Ministerio de Cultura, por el grupo de investigación liderado por el profesor 
Sánchez-Palencia, siendo conscientes desde la Fundación Las Médulas ${ }^{14}$, del potencial económico del yacimiento como recurso patrimonial y del problema que plantearía la coexistencia de la funcionalidad turística y económica con la funcionalidad cultural y arqueológica por excelencia. Hasta la actualidad no se ha declarado Parque Arqueológico, aunque el Aula Arqueológica -construida por la Junta de Castilla y León y gestionada por el Instituto de Estudios Bercianos [IEB]- facilita al público información característica de Parque -5 itinerarios, el punto de información Aula Arqueológica en Orellán y una guía arqueológica editada por la Junta de Castilla y León.

Las bases de la creación de un instrumento de planificación y gestión territorial de Las Médulas lo constituyó el Plan de Actuación y Usos del Espacio Cultural Las Médulas [PAU] (2013-2016) ${ }^{15}$, aprobado en 2013, y la Junta Rectora, como órgano gestor, constituida por 36 miembros, entre los que se encuentran juntas vecinales, Universidad, representantes de las tres administraciones del Estado $\mathrm{u}$ organizaciones sindicales.

\section{Figura 2: Figuras de protección vigentes en Las Médulas cuyo diagrama representa la yuxtaposición de las figuras territoriales sectoriales.}

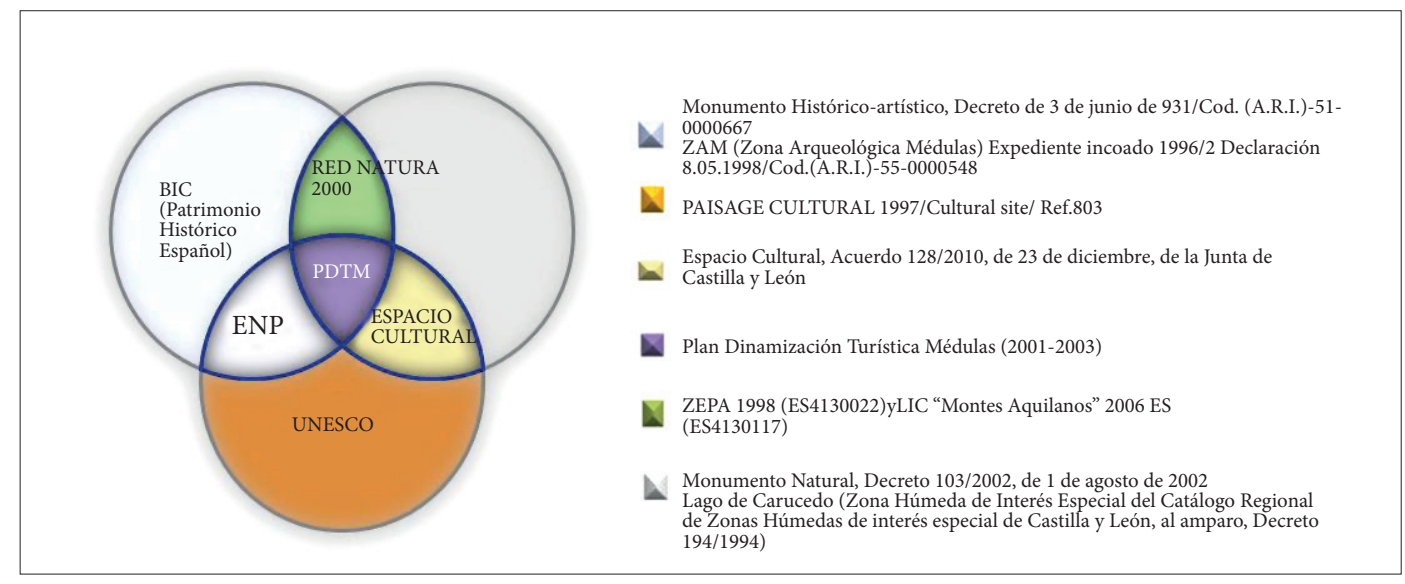

Fonte: Elaboración propia, 2017.

\section{El PDTM: un instrumento de cooperación turística fallido}

La valoración turística de Las Médulas, además de ser impulsada por la política turística del Estado, a través del PDTM, se produce por el uso turístico, el cual se vio incrementado desde la primera década de 2000. El Plan abanderaba una nueva cultura turística en destino, su activación constituía un nuevo modelo de intervención, y aunque contemplaba nuevas oportunidades, a través de la creación de productos turísticos y consolidación de la vocación turística, planteaba nuevos retos en la intervención integral en Las Médulas.

Uno de los aspectos más relevantes, desde el punto de vista geográfico, de los PDT (1996-2006), que fueron diseñados por la Secretaría de Estado de Comercio y Turismo del Ministerio de Economía, es que representaban un cambio ya consolidado en la política turística española a partir de la década de los 90 del siglo pasado, al haber superado como principal fundamento, la visión economicista de la política.

Desde los años noventa, la Administración Pública, asume un nuevo paradigma turístico basado en el desarrollo sostenible del turismo, afirmándose en la gestión responsable de los recursos turísticos. Así, en la generación de la política turística española de finales del siglo XX se diseñaron y aplicaron los Planes de Excelencia y Dinamización Turística, en el seno del II Plan Marco de Competitividad del Turismo Español (1996-1999) [FUTURES II], al que ha dado continuidad el Plan Integral de Calidad del Turismo Español [PICTE] hasta el año 2006, y el Plan del Turismo Español Horizonte 2020 aún vigente, dentro del cual se encuentran los Planes de Dinamización de Producto turístico, como un planteamiento renovado de los desaparecidos PDT, que presentaban un carácter más territorial. 
Los fundamentos de la interpretación territorial de la política turística española se pueden situar en los PDT, dentro del PICTE, que teniendo como referencia el principio de calidad, en su concepto más integral, el de la cooperación como instrumento básico de calidad del turismo y el papel estratégico de las entidades locales en la definición del destino (Brunet et al., 2005) convocaban a numerosos responsables del territorio. Los PDT superaban la visión sectorializada de los anteriores planes FUTURES, teniendo en cuenta de forma integral, los factores que integran el producto turístico y la complementariedad de las potencialidades existentes, aunque la capacidad de intervención de los PDT era escasa, debido a las limitaciones económicas y de gestión, relacionadas con su limitado presupuesto y la ausencia de competencias intersectoriales.

Entre los objetivos de los PDT se encuentran la valoración y uso turístico de recursos; estudio y diseño de políticas y estrategias de producto, precio y promoción, y comercialización; fortalecimiento e integración del tejido empresarial mediante el fomento del asociacionismo, asesoramiento y apoyo a las empresas; creación de nuevos productos basados en la explotación innovadora de los recursos, siempre en sintonía con la preservación del medio; articulación de los recursos, servicios, y oferta turística como producto y su integración como destino.

La construcción del centro de recepción de visitantes, la restauración de canales para caminos turísticos o la recuperación de galerías, constituyen acciones que han generado un valor añadido al territorio y han exigido la coordinación de diversos agentes del territorio.

Participaron en el PDTM como partes firmantes, los municipios de Borrenes, Carucedo, Priaranza del Bierzo y Puente de Domingo Flórez, a los que se adhirió Benuza. El Plan se firma en noviembre de 2001 en convenio de colaboración por una duración de cuatro años, entre el Ministerio de Economía, la Consejería de Comercio, Industria y Turismo de la Junta de Castilla y León, el Consejo Comarcal del Bierzo y la Asociación de Promotores de Turismo de Las Médulas. Por Convenio se acuerda <<que todas las partes consideran que la mejora de la competitividad turística de Las Médulas y su sostenibilidad económica, social y medioambiental precisa de un mejor de calidad del medio urbano y natural del municipio, una ampliación y mejora de los servicios públicos, adaptación a las tendencias de la demanda y la puesta en valor de nuevos recursos turísticos >> (Boletín Oficial del Estado, 2002, p. 3383).

Los objetivos descritos por Convenio fueron el aumento de la calidad de los servicios turísticos del destino; mejora del medio urbano y natural del municipio; ampliación y mejora de los espacios de uso público; mejora de los servicios públicos, aumento, diversificación y mejora de la oferta complementaria: puesta en valor de recursos turísticos, creación de nuevos productos, sensibilización e implicación de la población y agentes locales para la calidad; el desarrollo de una oferta de servicios turísticos, profesionalizados y de calidad; la creación de un órgano de cooperación y coordinación para la gestión del turismo. El Plan se aplica en un área total de 4.932 habitantes en 2001 (Instituto Nacional de Estadística [INE], 2016) con una escasa densidad, que registra una pérdida de población, en términos globales, en torno al 20 por ciento en 2016 (INE, 2017) con respecto a 2001.

Con el fin de cumplir con los objetivos, cada parte firmante adquirió una serie de compromisos Entre los relacionados más directamente con la gestión, se encuentran los del Consejo Comarcal, quien asumió la Gerencia del Plan. El papel del Consejo Comarcal resulta estratégico por el alcance de sus funciones político administrativas, que sobrepasa la ZAM; también, por su labor gestora del Plan y su papel en la planificación turística e intervención en el territorio, incluyendo labores de sensibilización con la población local.

De forma esquemática los objetivos recogidos en el Convenio son:

- Procurar el conocimiento y difusión de los objetivos y realizaciones del Plan entre la población y los agentes turísticos del municipio.

- Velar por el desarrollo de la actividad turística en la Comarca, en el ejercicio de sus competencias.

- Fomentar la sostenibilidad económica, social y medioambiental de los municipios y especialmente la calidad del medio ambiente urbano y natural y de los servicios públicos.

- Evitar el crecimiento incontrolado de los núcleos turísticos y de oferta de alojamiento.

- Velar por el estricto cumplimiento de la normativa urbanística y de ordenación territorial.

Los objetivos del Plan y las funciones otorgadas al Consejo defienden un nuevo modelo de intervención turística en la línea de los planteamientos del desarrollo turístico integral, sostenible y de base territorial (López, 2016, 2014) hasta entonces inexistente en la teoría y en la práctica, que utilice métodos innovadores en las fórmulas de colaboración en materia turística (Ivars, Rodríguez, Vera y Acebal, 2014). Las claves para el nuevo desarrollo se encuentran muy ligados al territorio y a un desarrollo más integral del turismo, esto incluye la mejora del medio ambiente urbano y natural del municipio, creación de oferta complementaria, valoración de recursos turísticos, sensibilización de la población, 
cooperación, y la sostenibilidad económica, social y medioambiental, ejerciendo cierto control sobre el crecimiento por parte de la acción pública (Velasco y Santos, 2016).

Aunque la condición de Paisaje Cultural Patrimonio de la Humanidad plantea problemas de intervención, al establecerse restricciones en el uso e intervención por parte de la Administración, la proyección turística que tiene, favoreció el incipiente desarrollo turístico. El turismo responsable ayudó a nuevas oportunidades para el desarrollo local, especialmente en un territorio en declive, cuya posibilidad de integrarse en el nuevo modelo de gestión integral del territorio podría beneficiarle en materia de conservación, calidad y cooperación, de acuerdo a las propuestas de ordenación de López Olivares (López, 2016a)-(López, 2016b), que deberían dar respuesta a los puntos débiles (Tabla 1).

Tabla 1: Claves del diagnóstico territorial

\begin{tabular}{|l|l|}
\hline Puntos fuertes & Puntos débiles (fase inicial) \\
\hline & $\begin{array}{l}\text { Ausencia de planificación de los recursos } \\
\text { Envejecimiento de le población }\end{array}$ \\
Valta de recursos humanos cualificados \\
Valor patrimonial de elementos culturales y & $\begin{array}{l}\text { Escaso capital de inversión de las Administraciones } \\
\text { públicas }\end{array}$ \\
Voluntad de la Administración local de emprender & Deficientes infraestructuras \\
uma politica de desarrollo socio económico & Escasa protección del patrimonio \\
Diversidad y calidad gastronómica & Falta de coordinación en materia de promoción \\
Inexistencia de masificación, estado incipiente de & Fuerte estacionalidad de la demanda turística \\
desarrollo turístico & Inadecuación de infraestructuras turísticas \\
& Escasa oferta complementaria \\
& Deterioro ambiental \\
& Desaparición de la tradición artesanal \\
& Falta de sensibilización de la población local hacia \\
\end{tabular}

Elaboración propia a partir de trabajo de campo, 2007.

Las actuaciones desarrolladas dentro del Plan durante las dos primeras anualidades se centran en la creación de nuevos productos y servicios al turista, y la valoración de recursos, uno de los aspectos más débiles del entorno, correspondiéndose con uno de los objetivos principales del Plan. El gasto refleja que las mayores inversiones se corresponden con actuaciones relacionadas con la rehabilitación y puesta en valoración (Figura 3, 4 y 5), seguido de la mejora del medio ambiente urbano y natural, y difusión del Plan.

\section{Figura 3: Distribución presupuestaria PDTM $1^{\text {a }}$ anualidad (\%) en la que se observa una mayor inversión en la creación de nuevos productos y servicios turísticos.}

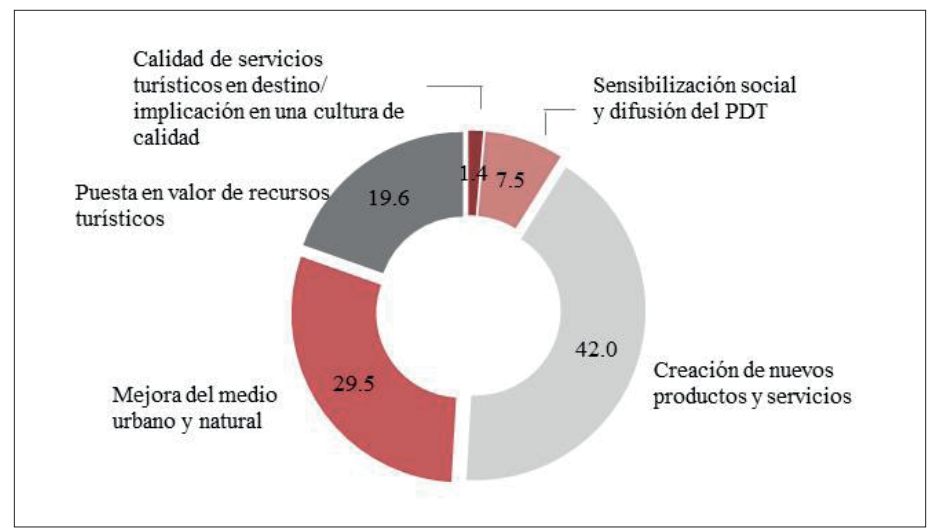

Elaboración propia a partir de Subdirección General de Calidad e Innovación Turística, 2007. 
Figura 4: Distribución presupuestaria PDTM $2^{a}$ anualidad (\%) en la que se observa un incremento de inversión en calidad de servicios turísticos en destino.

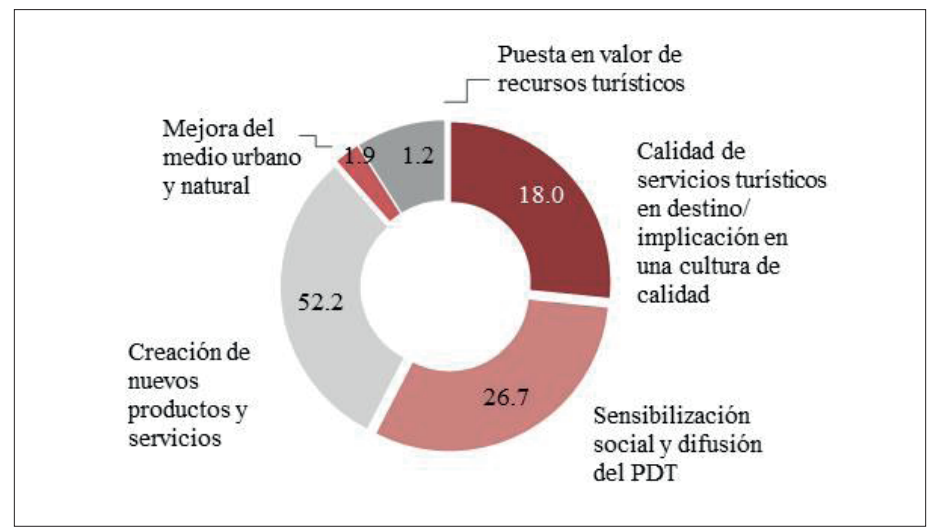

Elaboración propia a partir de Subdirección General de Calidad e Innovación Turística, 2007.

Figura 5: Distribución presupuestaria PDTM $3^{\mathrm{a}}$ anualidad (\%) en la que se observa un incremento presupuestario en la fase de sensibilización social y difusión del PDTM.

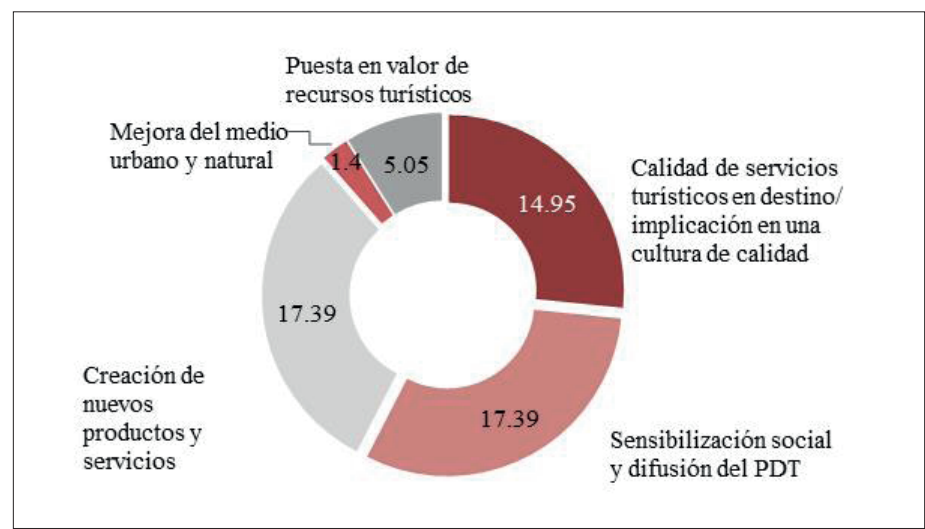

Elaboración propia a partir de Subdirección General de Calidad e Innovación Turística, 2007.

La consecución de algunas de las actuaciones se ha visto obstaculizada por requerimientos administrativos, por los correspondientes y tediosos permisos a otras entidades administrativas, o por la falta de colaboración de los actores territoriales, pero ¿Quiénes son los responsables y cuáles son los conflictos con los que se encuentra el PDTM?

Por un lado, la existencia de las distintas figuras sectoriales de protección favorece una yuxtaposición de competencias repartidas entre la Administración central y la autonómica. Por otro lado, son numerosos los agentes e intereses que actúan en el territorio, desde los actores relacionados con la investigación arqueológica y educativa -identificados en la Fundación Las Médulas-, a los relacionados con los servicios turísticos asociados al Consejo Comarcal. La figura de Paisaje Cultural ha puesto a prueba la capacidad de gestión y colaboración interadministrativa, al demandar la necesaria gestión integral que demanda esta categoría y el recurso del paisaje. 


\section{Las claves del conflicto en la gestión territorial}

La vocación cultural de Las Médulas es incuestionable. Las diversas figuras de protección cultural y los resultados de las investigaciones y actividades educativas que se desarrollan en el yacimiento por parte del IEB y la Fundación Las Médulas, dan fe de este hecho. A su vez, la dinámica funcional de Las Médulas (Monteserín, 2006) consolida la actividad turística como uno de los usos principales (Figura 6). La máxima afluencia de visitantes se registra a partir de 2001, en donde el Aula Arqueológica registra la llegada de 43.034 visitantes al edificio, registrando un crecimiento mantenido hasta la actualidad. Los conflictos existidos por la colocación de una caravana de información turística, gestionada por el Consejo Comarcal, junto al Aula, hasta la creación del Centro de visitantes, ha podido constituir un factor de disminución de los visitantes en el Aula Arqueológica, explicando los valles representados en la figura 6. Los datos proporcionados por el Consejo Comarcal acerca de las visitantes registradas en el Centro de recepción de visitantes, muestran cifras próximas a un centenar de visitantes anuales (tanto las visitas libres como guiadas - consta de un itinerario de $3 \mathrm{~km}$, fue adquirido por 27.847 visitantes en 2016 según dato proporcionados por el Consejo Comarcal (2017)-). El registro de visitantes del Aula Arqueológica permite observar el impacto de la reciente puesta en funcionamiento de la entrada conjunta -itinerario y visita al Aula Arqueológica-. Sigue superior el número de visitantes individuales en el Aula sin entrada conjunta, según los datos proporcionados por el IEB -8.406 en 2016-; este hecho es más significativo en el caso del uso de entradas conjuntas en grupos -949 frente a los 8.221 que visitan el Aula sin entrada conjunta, lo que podría explicarse por las características y motivaciones de un público más especializado.

Figura 6. Afluencia de visitantes 1999-2016 en la que se observa un incremento exponencial a principios de la década de 2000. Las visitas se concentran en los meses de marzo, mayo, agosto, octubre y noviembre, coincidiendo con períodos breves festivos.

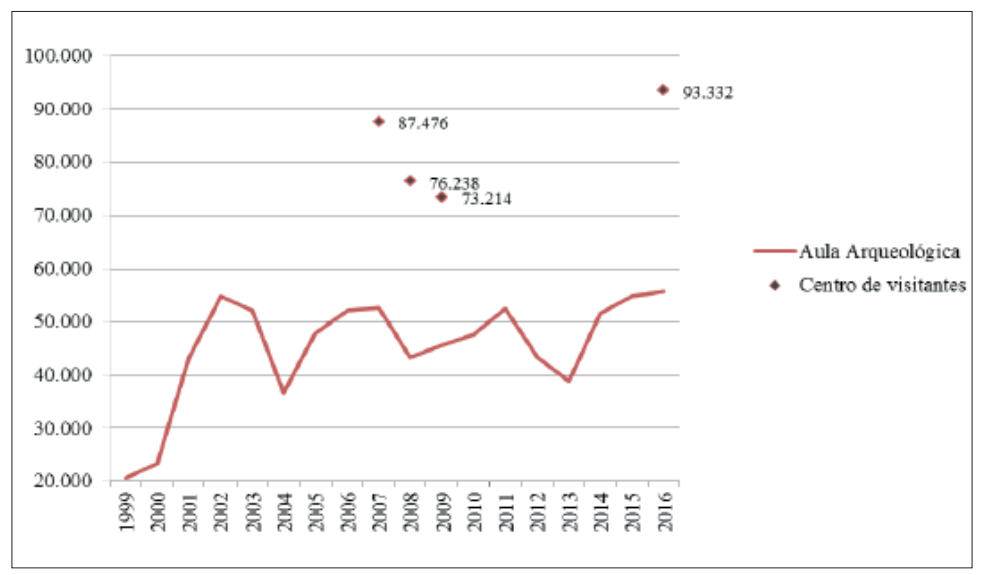

Elaboración propia, a partir de IEB y Consejo Comarcal del Bierzo, 2017.

Aunque el PDTM sentó las bases para el diseño de una estrategia turística sistémica desde abajo, el limitado plazo en el que se ejecutó, junto con la falta de coordinación entre los agentes y los trámites administrativos requeridos en las actuaciones, explican la ralentización y truncamiento de actuaciones de valoración y acondicionamiento de recursos turísticos.

La ejecución del Plan puso de manifiesto que la propia complejidad de la organización político administrativa del territorio -cinco municipios y una veintena de entidades menores locales, integradas en los municipios-; la distinta naturaleza política de las juntas vecinales; y la ausencia implícita de la suficiente legitimación del Consejo Comarcal en su función de Gerencia, por parte de responsables locales; y la yuxtaposición de figuras de protección existentes, constituirían los principales obstáculos para coordinar las múltiples dimensiones del recurso patrimonial (Figura 7). 
Figura 7: Claves del conflicto territorial del PDTM.

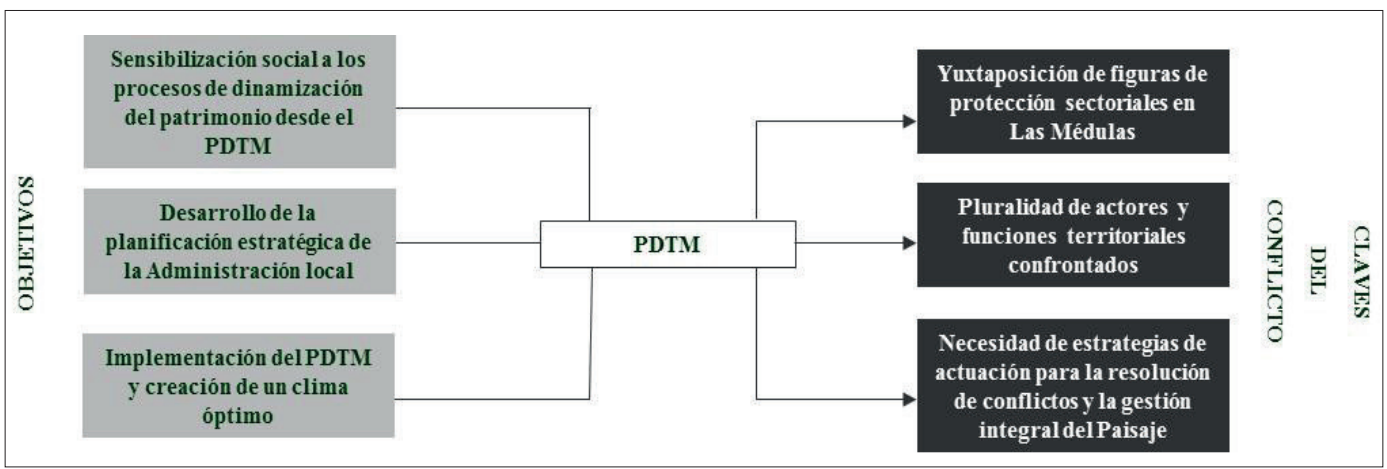

Elaboración propia.

Nos referimos a este espacio como un territorio de intervención múltiple al existir una pluralidad de actores, competencias administrativas y funcionalidades del recurso (Figura 8), lo cual hace más compleja la gestión territorial. Por un lado, la Fundación Las Médulas, creada en 1999, y el IEB, existente desde 1959, tienen carácter eminentemente cultural. Una de las principales acciones de la Fundación fue la creación del Aula Arqueológica. El Aula constituyó el primer espacio de interpretación y recepción de visitantes en este espacio. La función principal de ésta es la de colaborar con las administraciones públicas para la protección, conservación y desarrollo; trabajos de investigación en el yacimiento; y difusión del valor del Paisaje Cultural, participando con entidades públicas y privadas, mientras que el IEB tiene por objetivos la difusión y protección de la cultura y patrimonio a nivel comarcal.

\section{Figura 8: La colaboración entre los agentes con competencias en el territorio constituye un reto para una gestión territorial integral y efectiva.}

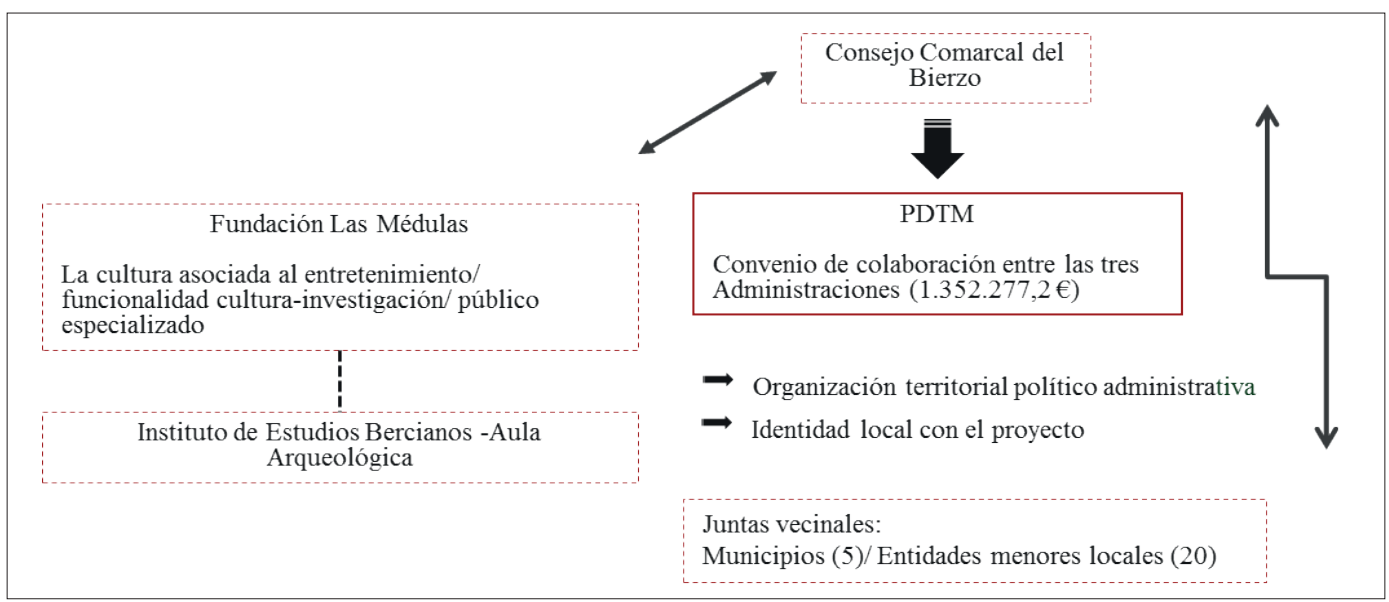

Elaboración propia.

Otros de los actores del territorio son el Consejo Comarca del Bierzo y el PDTM. El primero, es una institución de gobierno y administración de la Comarca ${ }^{16}$; se trata de una entidad local con competencias supramunicipales. Incluye treinta y ocho municipios con sus respectivas juntas vecinales. La condición de órgano gestor del Plan ha colocado al Consejo en una encrucijada, ante las negativas a que las decisiones y gestiones fueran tomadas y realizadas por parte de este órgano. Una de las explicaciones del rechazo por parte de los municipios, estaba relacionada con el hecho de que el Consejo era un órgano que 
consideraban ajeno a las administraciones municipales. Esta condición derivó en contiendas judiciales, como la de la Alcaldía de Borrenes y el Consejo, con motivo de la gestión del Aula Las Médulas ${ }^{17}$ situada en Borrenes. En 2008 el Tribunal Superior de Justicia de Castilla y León le dará la razón a la Alcaldía, devolviéndole la titularidad del edificio. Un hecho similar de enfrentamientos entre administraciones, se repetiría en 2016, relacionado con el Aula de interpretación de los canales en el municipio de Puente, cuya gestión reclama el municipio.

La creación y activación de recursos a partir de los centros de interpretación, ha constituido una de las principales actuaciones del Plan, junto con la creación de infraestructuras turísticas y el acondicionamiento de accesos. Pero existen actuaciones que, al requerir integrarse en proyectos globales y/o no haber sido diseñadas con la colaboración y aprobación de todos los actores, no han tenido el éxito esperado. En la primera anualidad, han sido la rehabilitación del edificio Aula de Puente (centro de interpretación $1^{\text {a }}$ fase), rehabilitación del edificio del centro de interpretación de Borrenes ( $1^{\text {a }}$ fase), puesta en valor de las Barrancas de Santalla, acondicionamiento del Lago de Carucedo ( $\left.1^{\mathrm{a}} \mathrm{fase}\right)$, recuperación de los Canales de Benuza, puesta en valor del asentamiento metalúrgico de Orellán -sendas y accesos-, gerencia del Plan, proyecto de señalización, señalización específica, propuesta de registro de marca, Plan de interpretación y comunicación del patrimonio Las Médulas y folleto- libro de Las Médulas.

El desarrollo de las actuaciones hace necesaria no solo el conocimiento acerca de la realidad territorial, sino también y, sobre todo, integrar la gestión y los intereses socioeconómicos bajo una estrategia global, un aspecto al que trataba de dar respuestas la elaboración del PAU ${ }^{18}$ de 2003. Los criterios rectores y sectoriales, según recoge el PAU, requieren de un órgano de aplicación, evaluación y control. Para este fin se creó la Junta Rectora y Asesora del Monumento Natural y Espacio Cultural de Las Médulas ${ }^{19}$, como órgano único de gestión y consultivo.

La Junta se encuentra adscrita a las secretarías generales de las respectivas consejerías de Patrimonio Cultural y Espacios Naturales. Está formada por treinta y seis miembros, entre los cuales se encuentran especialmente representadas las juntas vecinales y municipios afectados; representantes de las tres administraciones, siendo la Dirección General de Patrimonio la que representa la Administración central; asociaciones profesionales, empresariales y agrarias; el Consejo Superior de Investigaciones Científicas [CSIC]; Consejo Comarcal del Bierzo; organizaciones no gubernamentales; y representante de propietarios de superficie afectada. Sin embargo, no deja de ser un órgano administrativo, ante el cual algunos responsables, como la Alcaldía de Carucedo, se mostrarían escépticos.

En todo caso, la Junta Rectora representa un esfuerzo por unificar la gestión que hasta entonces recaía fundamentalmente en la Junta, el Consejo Comarcal y los ayuntamientos, pero aún resulta poco operativa en cuanto a un modelo de gestión integral; no gestiona directamente el paraje y la representación del Paisaje Cultural es escasa, o inexistente, en este órgano. En cuanto a la organización administrativa, la ausencia de convocatorias de reunión de la Junta, es otro de los aspectos objeto de crítica por el Consejo Comarcal, señalando que entre 2014 y 2016 no se había convocado reunión. La relación con la Junta Rectora produce algunos desencuentros entre los representantes de la Junta de Castilla y León -Delegado y Presidente- y el Consejo Comarcal, como refleja el informe jurídico de la Junta. Éste avala la ausencia de poder decisorio de la Junta Rectora ante la aprobación de un modelo de gestión, en el que el Consejo Comarcal estaría interesado en presentar, mientras que la propuesta de gestión de la Fundación Las Médulas habría sido rechazada por el Consejo Comarcal y los ediles municipales. Aunque éstos aprobaban el modelo, se mostraban partidarios de que recayera en el Consejo Comarcal la gestión y no en la Fundación, y abogando por un modelo mixto - público/privado-. Al margen de la Junta Rectora, esta entidad comarcal reivindica a la Junta de la Comunidad, mayores competencias territoriales, en un contexto en el que encuentran, en la denominada gerencia unificada, un punto de encuentro Junta y Consejo Comarcal. Sin embargo, el carácter integrado del modelo de gestión es cuestionable, considerando que se basa en una distribución de elementos y agentes, entre el Consejo, la Junta y el IEB, que intenta unificar la gestión a partir de la distribución de competencias en los distintos elementos, en materia de gestión.

La Fundación Las Médulas será la encargada de ejecutar el Plan 2020. Este Plan es impulsado y financiado por la Consejería de Cultura y Turismo de la Junta, con el fin de promover iniciativas de protección y difusión del patrimonio. Cuenta con un presupuesto de 600.000 euros para el trienio 2015-2018, -la inversión total del PDTM fue de 1.352.277,2 euros de los que el Consejo Comarcal efectuaría su aportación con cargo a la aplicación presupuestaria 751.601 la cantidad de 150.253,02 para el trienio 2001, 2002 y 2003 respectivamente-.

Las actuaciones del Plan 2020, apoyadas por el IEB, van encaminadas a favorecer la conservación activa y el desarrollo territorial, creando nuevos productos culturales con función turística -Campo de 
trabajo para la investigación arqueológica y visita, señalización de itinerarios, acondicionamiento de asentamientos, o la introducción de Tecnologías de Información Geográfica [TIG] en la experiencia de la visita-.

El hecho de que el modelo de gestión unificado se base más en un modelo de distribuciones competenciales, se aleja de ser un modelo de gestión integrada. Aunque la pretensión de la Junta Rectora era la de aunar bajo una misma gestión este espacio cultural y natural, no acaba de resolver los problemas de gobierno. Si bien, uno de los aspectos a favor es el hecho de que haya favorecido un punto de encuentro entre los diversos actores que intervienen en el territorio, aunque tanto el modelo de gestión como el Plan 2020, no estén exentos de ser cuestionados entre los propios responsables. En la actualidad sigue existiendo el reto de definir una estrategia de actuación para la resolución de los conflictos y la gestión integral del Paisaje Cultural.

\section{Conclusiones y estrategias para la resolución de conflictos y la gestión integral del Paisaje}

Los PDT se diseñaron como un instrumento de planificación estratégica con una base territorial local para la dinamización turística integral. Al mismo tiempo, constituyeron, en muchos casos, una herramienta favorable a la creación de un clima óptimo para surgir iniciativas de desarrollo. Sin embargo, el PDTM desencadenó problemas latentes en materia de gestión territorial. Los principales problemas estarían relacionados con la débil coordinación y colaboración de los distintos agentes implicados en el plan debido, principalmente, a desencuentros de naturaleza política y/o a la escasa legitimidad con que las juntas vecinales y otros actores, asumieron como Gerencia al Consejo Comarcal, a lo que se sumaría la escasa sensibilización de la población local hacia el Plan.

Otra de los escollos estaría relacionado con la funcionalidad de la ZAM. Tras la continuada labor investigadora en el ámbito de la Arqueología, la actividad turística era considerada con ciertas reservas por parte de los agentes culturales.

La dimensión cultural y ambiental, reconocida por los distintos órganos e instituciones a nivel autonómico, nacional e internacional, se estaba desarrollando sin que existiera una figura de planificación territorial turística que favoreciera la conciliación de la función turística con la cultural, especialmente en un territorio frágil y en declive como éste, donde hubiera sido catastrófico un modelo de explotación turística localizado, intensivo y básicamente economicista.

En este territorio de intervención múltiple existe aún un inconveniente de funciones y competencias territoriales. Se trata de un espacio complejo, al considerar, no solo los agentes que intervienen en el espacio, sino también por la suma de figuras de protección de naturaleza sectorial. No es hasta la declaración de Paisaje Cultural que se supera la visión parcial del valor patrimonial. A su vez, se planteará la necesidad de un modelo de gestión más integral.

Aunque los PDT se enfocaban en la creación y demostración del valor de los recursos territoriales con un enfoque integral, éstos contaban con una limitada capacidad financiera y temporal. Lo más importante desde el punto de vista de la intervención territorial, es que el PDTM constituyó un factor clave para conocer la realidad de la gestión territorial.

La ejecución de las actuaciones que se llevaron a cabo dentro del PDTM desencadenó conflictos por las competencias y la legitimidad de los recursos, pero también permitió reforzar la identidad con el Paisaje Cultural y concienciar del valor del entorno. En 2015, la Junta desautoriza la actividad de la cantera de Peña del Rego a la empresa Catisa, que con una extensión superior a 60 ha, explota los áridos en Las Médulas desde 1968, contando con licencia del municipio de Carucedo, al haber antepuesto las ventajas económicas cortoplacistas. La explotación fue paralizada tras ratificación del Tribunal Superior de Justicia [TSJ] y ser declarada incompatible con el valor de la zona, y procesada por vía penal.

El PDTM puso de manifiesto la conveniencia de un sistema de gestión participativo que constituyera un un modelo de coordinación y colaboración, con la única cabida del uso social del patrimonio de manera sostenible. La valoración del recurso patrimonial sentó las bases para pensar en un desarrollo turístico más integral y de calidad, articulado a las dinámicas territoriales de Las Médulas.

De forma esquemática, se identificaron los siguientes puntos como conclusiones finales:

i) Existe un problema de funcionalidad cultural-didáctica y turística, aunque con el transcurso del tiempo se han tratado de conciliar.

ii) Hay yuxtaposición de herramientas de ordenación e instrumentos de planificación sectorial.

iii) La gestión del producto turístico responde, sobre todo, a estrategias económicas y a favor de intereses de municipios. Con el transcurso del tiempo se han realizado avances en el 
planteamiento del sistema de gestión, es el caso de la entrada única, sin embargo, dista de ser un sistema integral de gestión.

iv) En relación a la creación de productos, el contenido es más una tematización teórica del territorio que una representación de su identidad local, podría ser el caso del centro de interpretación de las mariposas.

v) La planificación turística no ha resuelto la desarticulación en el territorio y este hecho perjudica el buen desarrollo de las actuaciones turísticas.

vi) Existencia de conflictos de competencias en algunos ámbitos, es el caso de la señalética.

vii) La Gerencia del Plan no contó con la colaboración de todos los municipios.

viii) Escasa sensibilización y participación social en el PDTM.

ix) Un aspecto favorable es que el PDTM ha movilizado intereses y ha favorecido nuevos procesos de descentralización y gestión, aún sin resolver.

A pesar de la existencia de una figura de protección integral como es la del Paisaje Cultural, el diseño de una estrategia conjunta para el territorio es una tarea pendiente. El turismo puede abrir nuevas vías de encuentro en la gestión del territorio. Conviene señalar que la suma o la distribución de competencias y elementos para su gestión, aunque permite la participación de los diferentes agentes, no constituye la gestión integral del territorio. Asimismo, a pesar de los avances habidos, el concepto global del paisaje y los estudios de tipo diagnóstico han tenido un escaso impacto en la planificación.

\section{Agradecimientos}

Por la colaboración en el transcurso del trabajo, al Consejo Comarcal, Aula Arqueológica las Médulas, IEB, Alcaldía de Borrenes, Carucedo y Puente Domingo Flórez, Asociación de Promotores de Turismo de Las Médulas y Subdirección General de Calidad e Innovación Turística.

\section{Bibliografía}

Benito, P., Calderón, B, y Pascual, Henar

2016. La gestión territorial el patrimonio industrial en Castilla y León (España): fábricas y paisajes. Investigaciones geográficas México, 90. Recuperado de < http://dx.doi.org/10.14350/rig.52802>

Bouazza, O.

2016. La participación ciudadana en el proceso planificador. Fundamento constitucional y legal. Review International Won Sustainable Housing and Urban Renewal: RI-SHUR, 4, 37-49.

Brunet, P., Almeida, F., Coll, M., y Monteserín, O.

2005. Los Planes de Excelencia y Dinamización Turística, un instrumento de cooperación a favor del desarrollo turístico. Boletín de la Asociación de Geógrafos Españoles [BAGE], 39, 201-226

Cañizares, M. C.

2011. Patrimonio, parques mineros y turismo en España. Cuadernos de Turismo, 27, 133-153.

Capel, H.

1996. La rehabilitación y el uso del patrimonio histórico industrial. Documents d’Analisis Geográfica, 29, $19-50$.

Comisión Europea.

1999. Estrategia Territorial Europea: Hacia un desarrollo equilibrado y sostenible del territorio de la UE. Postdam: Oficina de Publicaciones Oficiales de las Comunidades Europeas. Accesible en http:// ec.europa.eu/regional_policy/sources/docoffic/official/reports/pdf/sum_es.pdf

Comité Internacional para la Gestión del Patrimonio Arqueológico.

1990. Carta Internacional para la Gestión del Patrimonio Arqueológico. Carta de Lausana.

Conferencia Europea de Ministros responsables de ordenación del territorio.

2000. Principios Directores para el Desarrollo Territorial Sostenible del Continente Europeo, Hannover. Consejería de Cultura y Turismo de Castilla y León.

2005. Plan PAHIS 2004-2012 del Patrimonio Histórico de Castilla y León. Dirección General de Patrimonio y Bienes Culturales. 
Consejo de Europa.

2000. Convenio Europeo del Paisaje. Florencia

Convenio de Colaboración entre el Ministerio de Economía, la Consejería de Industria, Comercio y Turismo de la Junta de Castilla y León, el Consejo Comarcal del Bierzo y la Asociación de Promotores de Turismo de Las Médulas, para el desarrollo de un Plan de Dinamización Turística en Las Médulas.

2002. Subdirección General de Calidad e Innovación Turística. Recuperado de <http://www.boe.es/ diario_boe/txt.php?id=BOE-A-2002-1568>

Díaz, P, Santana, A. y Rodríguez, A.

2013. Destination, image at destination. Methodological aspects [Destino, imagen en destino. Aspectos Metodológicos] Pasos: Revista de turismo y patrimonio cultural, 3 (11): 83-95.

Díaz, P, Santana, A. y Rodríguez, A.

2015. Re-significando lo cotidiano, patrimonializando los discursos. Desacatos: Revista de Antropología Social, 47: 72-89.

España, Ministerio de Economía y Hacienda.

1998. Planes de Excelencia y Dinamización Turística. Madrid: Secretaría de Estado de Comercio, Turismo y Pyme.

España, Ministerio de Economía.

1999. Plan Integral de Calidad del Turismo Español 2000-2006. Madrid: Secretaría General de Turismo. Fernández-Posse, M. D., Menéndez, E., y Sánchez-Palencia, F. J.

2002. El paisaje cultural de las Médulas" Treballs d’Arqueologia, 8: 37-61.

García Canclini, N.

1999. Los usos sociales del Patrimonio Cultural. En Aguilar , E. (coord.): Patrimonio Etnológico. Nuevas perspectivas de estudio: Consejería de Cultura, Junta de Andalucía, Granada, 16-33.

Hortelano, L. A.

2011. Turismo minero en territorios en desventaja geográfica de Castilla y León: recuperación del patrimonio industrial y opción de desarrollo local. Cuadernos de Turismo, 27: 521-540.

Instituto del Patrimonio Cultural de España.

2011. Plan Nacional de Patrimonio Industrial. Ministerio de Educación, Cultura y Deporte.

Instituto Nacional de Estadística

2017. Revisión del Padrón Municipal. Recuperado de http://www.ine.es/jaxiT3/Tabla.htm?t=2877\&L=0 Ivars, J. A., Rodríguez, I., Vera, J. F. y Acebal, A.

2014. Nuevos enfoques en gestión turística: el programa de agrupaciones empresariales innovadoras en España. Boletín de la Asociación de Geógrafos Españoles [BAGE], 66, 369-395.

Junta de Castilla y León.

2008. Plan Estratégico de Turismo de Castilla y León 2009-2012. Valladolid, Consejería de Cultura y Turismo.

Junta de Castilla y León.

2011. Plan de Uso y Gestión del Espacio Cultural Las Médulas. Consejería de Cultura y Turismo. Valladolid: González, F.J. (Coord.)

López, D.

2016a. Sostenibilidad en los modelos actuales de gestión turística. Papers de turisme. 59, 88-89.

Recuperado de <http://www.papersdeturisme.gva.es/ojs/index.php/Papers/article/view/471/398> López, D.

2016b. El proceso metodológico general de formulación e implementación de planes de ordenación territorial de áreas turísticas. En Simancas, M. (coord.), La planificación y gestión territorial del turismo. (115-132). Madrid, España: Síntesis.

López, D. y Pulido, J. I.

2009. Desarrollo Turístico integrado. La actividad turística española en 2008. Castellón: AECIT, Madrid: Editorial Universitaria Ramón Areces.

Monteserín, O.

2006a. La interpretación y puesta en valor del territorio: Los Planes de Dinamización Turística. En M.A. Troitiño, M. García, García, J.S. (Coords.), Destinos Turísticos: viejos problemas inueva soluciones? Actas X Coloquio de Geografía del Turismo, Ocio y Recreación (p Universidad Complutense de Madrid (pp. 269-279). Cuenca, España: Unviersidad de Castilla La Mancha. 
Monteserín, O.

2006b. Las transformaciones territoriales en torno al turismo y al patrimonio industrial: La dinámica funcional de Las Médulas. En A. J. Lacosta, (Coord.), Turismo y cambio territorial; ¿Eclosión, aceleración, desbordamiento? (pp. 205-2016). Zaragoza, España: Prensas Universitarias de Zaragoza. Pp. 205-216. Ortega, J.

1998. El patrimonio territorial: El territorio como recurso cultural y económico. Ciudades: Revista del Instituto Universitario de Urbanística de la Universidad de Valladolid, 4, 33-48.

Pérez, L.C., Sánchez-Palencia, F.J., Fernández, J., Orejas, A. y Fernández-Posse, M.D.

1998. Las Médulas (León), la formación de un paisaje cultural minero. Boletín geológico y minero, 5-6 (109), 157-168.

Sánchez-Palencia, F.J., Fernández-Posse, M.D., Fernández, J., Orejas, A., Pérez, L.C. y Sastre, I.

2000. Las Médulas (León), un Paisaje Cultural Patrimonio de la Humanidad. Trabajos de Prehistoria, 57 (2): 195-208.

Troitiño, M. A.

noviembre 2003. Patrimonio Cultural: Valorización económica y reutilización funcional. En: Culturninnova. Jornadas de Gestión Cultural. La Palma, España.

Valenzuela, M. y Palacios, A.J.

2008. La valorización turística del patrimonio minero en entornos rurales desfavorecidos. Actores y experiencias. Cuadernos de Turismo, 22: 231-160.

Velasco, M., y Santos, R.

2016. La relación entre acción pública y turismo desde diversas perspectivas: ideas, actores e instituciones. Pasos: Revista de turismo y patrimonio cultural, 3 (14): 573-576.

\section{Notas}

1 Monumento Histórico-artístico por Decreto de 3 de junio de 1931 pasa a tener la denominación de BIC a tenor de la Disposición Adicional Primera de la Ley 16/1985, de 25 de junio, del Patrimonio Histórico Español. Expediente incoado por Resolución de 22 de octubre de 1996, de la Dirección General de Patrimonio y Promoción Cultural, de la Consejería de Educación y Cultura, por la que se acuerda tener por incoado expediente para la delimitación de la zona afectada por la declaración de la zona arqueológica de «Las Médulas», en Las Médulas y Orellán (municipio de Carucedo, Puente Domingo Flórez y Borrenes), León. <<BOE núm. 278, de 18 de noviembre de 1996, páginas 34906 a $34908>>$

2 Decisión del Comité Internacional de la UNESO, de 4 de diciembre de 1997 en Nápoles, donde acordó incluir a las Médulas en el listado de Patrimonio de la Humanidad de la UNESCO en base a los criterios (i)(ii)(iii)(iv).

3 ACUERDO 29/2013, de 25 de abril, de la Junta de Castilla y León, por el que se aprueba el Plan de Adecuación y Usos del Espacio Cultural de Las Médulas (León).

4 Trabajo inédito sobre laintervención realizada en el Seminario de Investigación: Ciudades Patrimonio de la Humanidad de España y México: experiencias comparadas de planificación y gestión sostenibles (21 a 28 de junio), Grupo de investigación Patrimonio, turismo y desarrollo, Universidad Complutense, Madrid, 2010.

5 http://ec.europa.eu/regional_policy/sources/docoffic/official/reports/pdf/sum_es.pdf

6 INSTRUMENTO de Ratificación del Convenio Europeo del Paisaje (número 176 del Consejo de Europa), hecho en Florencia el 20 de octubre de $2000<<$ BOE núm. 31, de 5 de febrero de $2008>>$.

7 ACUERDO 128/2010, de 23 de diciembre, por el que se declara Espacio Cultural el Bien de Interés Cultural denominado Las Médulas (León) (BOCYL núm. 250, de 29 de diciembre de 2010). Expediente incoado por RESOLUCIÓN de 11 de diciembre de 2008, de la Dirección General de Patrimonio Cultural.

8 Expediente incoado por la Dirección General de Patrimonio y Bienes Culturales, por Resolución de 5 de julio de 2005. ACUERDO 200/2007, de 26 de julio, de la Junta de Castilla y León, por el que se declara la ampliación del Bien de Interés Cultural con categoría de Zona Arqueológica denominado "Las Médulas» (León) a un total de 1. Mina romana de oro de Las Médulas (2.998,0 ha.); 2. El Castro o La Corona del Cerco de Borrenes (31,4 ha.): 3. El Castrelín de San Juan de Paluezas (11, 9 ha).

9 DECRETO 194/1994, de 25 de agosto, por el que se aprueba el Catálogo de Zonas Húmedas y se establece su régimen de protección. <<Boletín núm. 168, de 31 de agosto de 1994>>

10 DECRETO 103/2002 de 1 de agosto de la Junta de Castilla y León, formando parte de la red de Espacios Naturales de Castilla y León según la Ley 8/1991, de 10 de mayo, de Espacios Naturales de la Comunidad de Castilla y León.

11 Red Ecológica Europea de Zonas de Especial Conservación (ZEC), en base a la Directiva Hábitat de la Unión Europea (92/43(CEE) transpuesta a la normativa española por R.D. 1997/1995 y R.D. 1193/1998, y Directiva 79/409/CEE Aves Silvestres de Europa, también regulados por Ley 42/2007 de 13 de diciembre del Patrimonio Natural y de la Biodiversidad.

12 El Juzgado de lo Contencioso anularía el permiso de licencia ambiental aprobado por el representante de la Administración local municipal, ratificado por el TSJ en 2012.

13 Sánchez-Palencia, F.J.; Fernández-Posse, M. D.; Fernández Manzano, J.; y Báez Mezquita, J.A. (dir.). 1994. Parque Arqueológico de Las Médulas. Anteproyecto. Junta de Castilla y León. Dirección General de Patrimonio y Promoción Cultural. Madrid. Inédito.

14 Fundación Las Medulas, entidad sin ánimo de lucro dedicada a la puesta en valor de Las Médulas. 
15 ACUERDO 29/2013, de 25 de abril, de la Junta de Castilla y León, por el que se aprueba el Plan de Adecuación y Usos del Espacio Cultural de Las Médulas (León). <<BOCYL núm. 81, de 30 de abril de 2013>>.

16 Reconocida por Ley reconocida por Ley 1/1991, de 14 de marzo, por la que se crea y regula la Comarca de El Bierzo.

17 Recuperado de http://www.diariodeleon.es/noticias/bierzo/borrenes-aduena-aula-medulas-cambiar-cerraduras_182227. html [2 de marzo de 2007]

18 DECRETO 101/2002, de 1 de agosto, por el que se aprueba el Plan de Ordenación de los Recursos Naturales del Espacio Natural de Las Médulas. <<BOCYL núm. 151, de 6 de agosto de 2002>> .

19 Decreto $15 / 2013$, de 25 de abril. 